\title{
OvSynch protocol and its modifications in the reproduction management of dairy cattle herds - an update
}

\author{
Arkadiusz Nowicki, Wojciech Barański, \\ Agnieszka Baryczka, Tomasz Janowski \\ Department of Animal Reproduction with Clinic, Faculty of Veterinary Medicine, \\ University of Warmia and Mazury, 10-719 Olsztyn, Poland \\ arkadiusz.nowicki@uwm.edu.pl
}

Received: March 14, $2017 \quad$ Accepted: August 25, 2017

\begin{abstract}
Current knowledge about the function of the reproductive tract and appropriate use of hormonal drugs affords control of the oestrus cycle of cows. One of the hormonal protocols is OvSynch, which enables artificial insemination (AI) to be performed at the precise optimum time without control of the ovaries and uterus. Use of such protocols in reproductive management allows oestrus cycles to be synchronised and cows to be effectively inseminated without oestrous detection, which is time-consuming and difficult in farms with numerous cows. Therefore, OvSynch has become the first management tool for AI and is an alternative method to heat detection. Over the 20 years since its first implementation, OvSynch has been modified many times to improve its reproduction outcomes and widen its use. Besides its original use for heat synchronisation, it is also used in many ovarian disorders as a therapeutic method. This review article describes the possibilities which OvSynch provides, its current modifications, various applications, and the advantages and disadvantages of its use in practice.
\end{abstract}

Keywords: cows, oestrous cycle, synchronisation, OvSynch.

\section{Introduction}

A traditional method for noticing cows in heat is by observation, which is a time-consuming procedure (28). Unfortunately, many factors shorten the duration of heat and also weaken the behavioural signs of the phenomenon. Increasing milk yield, imbalanced feed ration, stress including heat stress, and welfare provision are the main factors influencing heat expression $(38,63)$. Additionally, the worldwide tendency to increase the number of animals in herds is leading to management problems for workers. To improve heat detection additional tools such as tail painting or pedometers are used $(28,39)$. However, even these methods cannot guarantee that every cow in heat will be found and inseminated. Generally, in recent decades oestrous rate detection has decreased to $60 \%$ (25). Thus there is still a need to improve heat detection and insemination success rate. To make oestrous detection more efficient and less time- consuming for staff, hormonal protocols have been invented and implemented into reproductive management (46, 57). Implementation of such protocols simultaneously improves quality of life for the farmers and minimises the costs of artificial insemination (AI). These hormonal schemes allow heat and ovulation to be synchronised, and in combination with timed AI (TAI) they render heat detection unnecessary. As a new trend in bovine reproduction and different impetus for hormonal protocols, there is a tendency to inseminate as many cows as possible until the $100^{\text {th }}$ day after parturition. Early introduction of protocols about 30-40 days postpartum facilitates this, since many can be inseminated as early as possible $(30,36)$. One such protocol is OvSynch, which is used for the whole herd and allows shortening the days until opening and the successful insemination of numerous cows until the $100^{\text {th }}$ day postpartum; this maximises milk production and improves operational economy. However, it must be remembered that if this protocol is 
used for all cows without each animal having undergone previous gynaecological examination, some animals will not respond due to undetected reproductive disorders such as true anoestrus, ovarian cysts, and endometritis (40, 43) Thus, an individual approach to animals in the herd is also preferred, including preliminary examination of the cows and their assignment on this basis either for hormonal synchronisation or treatment, if necessary. This review presents the opportunities for synchronisation of the oestrus cycles and treatment regimens by the use of the OvSynch protocol, and considers its limitations for veterinary practitioners.

The follicles, during their growth up to the size of around $9 \mathrm{~mm}$, become sensitive to luteinising hormone (LH) and as a consequence it is possible to accelerate their maturation by injecting exogenous hormones (32, 67). They can be used case-by-case, according to the results of the gynaecological examination, or in blanket application, assuming a similar developmental stage of follicles in all cows. OvSynch (Fig. 1) is an example of such an injection protocol, and it leads to the equalisation of follicle development on the ovaries, causes ovulation, and enables AI (46). This programme assumes that the first gonadotropin-releasing hormone (GnRH) injection induces the ovarian follicle to ovulate, which leads to development of the corpus luteum (CL). The efficiency of ovulation induction by the first GnRH injection varies from $66 \%$ to $85 \%$ (44, 58 ) and depends on the maturation stage of the follicles

\section{Basic goal of the OvSynch protocol}

(8) at the time of treatment. Ultrasound detection of the first developing follicles of a new wave is possible two days after GnRH injection (56) and one of these follicles will be used for TAI at the end of the OvSynch protocol. On the seventh day of OvSynch, prostaglandin $\mathrm{F} 2 \alpha\left(\mathrm{PGF}_{2} \alpha\right)$ is injected both to induce luteolysis and to allow the continuing development of the dominant follicle of the next wave.

In turn, this follicle will be estimated to ovulate by the second GnRH injection on day 9 of the protocol. Insemination should be performed blindly 16-24 hours later.

OvSynch gives the best results when used for the whole herd. This strategy allows all the cows designated for AI to be inseminated at a similar time postpartum, and the pregnancy rate in the herd to be improved $(45,46)$. However, it does not improve the reproductive performance of the herd when used only for selected, problematic cows. The advantages and disadvantages of the OvSynch protocol are summarised in Table 1. The main benefit of hormonal programmes such as OvSynch is the reduction of the number of undetected oestrous cows which could be potentially inseminated and made pregnant (45). The first insemination rate (FIR) in the OvSynch protocol reaches about $35 \%$, confirming that it is a good alternative to heat detection $(45,48)$. A higher percentage of pregnancies $(47.7 \%)$ obtained with the use of the OvSynch protocol was reported by Vasconcelos et al. (60). The pregnancy rate after OvSynch was better when TAI was performed 16 hours after the second GnRH injection (45\%), and a $41 \%$ rate was returned when performed 8 or $24 \mathrm{~h}$ after $\mathrm{GnRH}$ (47).

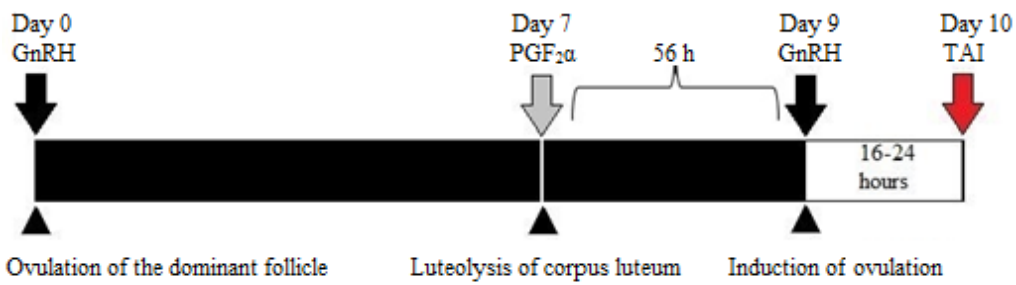

Beginning of the new follicular wave

Fig. 1. Scheme of OvSynch protocol

Table 1. Benefits and drawbacks of OvSynch protocol

\begin{tabular}{|c|c|}
\hline Advantages & Disadvantages \\
\hline Application possible in all cows & Possibility of AI in cows with reproductive disorders \\
\hline $\begin{array}{l}\text { Reduction of need for heat detection and gynaecological } \\
\text { examination }\end{array}$ & $\begin{array}{l}\text { Highest efficiency limited to start of protocol between } 5^{\text {th }} \text { and } 9^{\text {th }} \text { days } \\
\text { of cycle }\end{array}$ \\
\hline Shortening intercalving and voluntary waiting periods & Increased embryonic mortality rate \\
\hline Synchronisation of work in herd & Cost of hormones \\
\hline Possible therapeutic/cure effects & Different responses to hormonal treatment \\
\hline Fertility comparable to other methods & Poor fertility in heifers \\
\hline
\end{tabular}


Dirandeh (24) synchronised cows on the $30^{\text {th }}$ day after parturition and increased the efficiency of AI. The OvSynch protocol began six days after detecting heat signs, i.e. when follicles were able to respond to GnRH injection. In this group of cows the ovulation rate and pregnancy rate on the $60^{\text {th }}$ day after AI were $82.5 \%$ and $28.9 \%$ respectively. After the second GnRH injection in the control group, in which the programme began at any moment of the cycle, only $75.8 \%$ of cows ovulated and $23.2 \%$ of cows were pregnant on the $60^{\text {th }}$ day after AI. This observation shows that the time of the beginning of the OvSynch protocol influences its effectiveness, and the highest pregnancy rate was achieved when a follicle from the first wave was used for TAI. In view of this, some authors suggest that gynaecological examination or presynchronisation (e.g. Pre-Synch) may improve the fertilisation rate after OvSynch $(3,34)$. However, generally the OvSynch protocol was invented to eliminate heat detection. Nevertheless, the cited results contested this assumption. The weaknesses of the protocol which make it less effective are failure of the first ovulation or lack of luteolysis. The lower ovulation rate in numerous animals (only 54\% of ovulation) was described by Pursley et al. $(46,48)$, showing poorer reproductive results of OvSynch in heifers. Studies performed by other authors also confirmed poor efficiency of the OvSynch protocol in heifers $(55,64)$. Pursley et al. (46) compared the percentage of pregnant cows and heifers after using the hormonal programme for ovulation synchronisation. The pregnancy rates in the groups of heifers differed starkly, with $35.1 \%$ in the OvSynch group and $74.4 \%$ when using $\mathrm{PGF}_{2} \alpha$ in the control group. In contrast, the rates in cows were quite similar, $37.8 \%$ - in the OvSynch group vs $38.9 \%$ - in control group (48). These differences were caused by a lower ovulation rate after the first GnRH injection in heifers. This phenomenon was in line with the lower concentration of progesterone in the blood on the day of $\mathrm{PGF}_{2} \alpha$ injection in heifers than in cows. The concentration of this hormone in $86.2 \%$ of cows was typical for the luteal phase $(>1 \mathrm{ng} / \mathrm{mL})$, whereas in the group of heifers only $59.5 \%$ of animals reached this level $(46,48,55)$. This fact suggests that in heifers reproductive performance could be better using another protocol, for example Double OvSynch $(53,55)$.

The second phenomenon that can reduce the efficiency of OvSynch is non-occurrence of luteolysis after $\mathrm{PGF}_{2} \alpha$ injection (15). As a consequence, the development of the second follicular wave will be suppressed, which makes the synchronisation of ovulation and TAI impossible. Many studies stress the detrimental effect of this phenomenon on fertility. A second $\mathrm{PGF}_{2} \alpha$ injection $24 \mathrm{~h}$ later has been proposed to overcome this problem and to improve the fertility in OvSynch-synchronised cows (12).

\section{Other indications for OvSynch}

Silent heat. Lack of oestrous signs is an increasing problem on many farms. Today this phenomenon affects $10 \%-40 \%$ of dairy farms (69), while over 25 years ago its prevalence was less than 5\% (68). The reason for silent heat may be poor heat detection, but on the other hand, the shortening of oestrous duration and weakening of its signs have been confirmed in high-milk-yielding cows (61). As a main reason for this, negative energy balance and related endocrine alterations such as lower LH and oestrogen secretion have been considered (13, 61). Thus a reasonable solution for cows with silent or unobserved heat seems to be the use of hormonal protocols. These treatments allow precisely timed insemination of cows at the same optimum moment as TAI without heat detection. OvSynch applied to only such cows or as a part of reproduction management in the whole herd makes heat detection unnecessary. At the herd level, the decision must be taken how and when the postpartum OvSynch protocol should be administered in cows with silent heat. It can be started after gynaecological examination only in cows with active ovaries or without examination in cows known to have had silent heat in the past. The third possibility is blanket synchronisation of all cows after a voluntary waiting period. The total pregnancy rate after OvSynch can reach $35 \%-60 \%(26,64)$. Such encouraging reproductive outcomes are the basis for recommendation of this method for cows with silent heat. However, independently of the hormonal protocols, heat detection should be improved and feed ration should be corrected as preventive measures.

Heat stress. Heat stress reduces reproductive performance but farms with animals suffering from it may mitigate this with OvSynch. As a synchronisation protocol, it can be also used as a treatment method during heat stress, and it has been shown that beginning the protocol on the sixth day of the second cycle after parturition improved the fertility rate during periods of consecutive hot days (24). Thus, the OvSynch protocol may be used successfully for this purpose during summer when oestrous behaviour is exhibited and the percentage of successful inseminations is lower due to high temperatures $(2,21)$. Heat stress disturbs the periodicity of the ovaries, reduces progesterone level in the blood (2), may cause cyst development (39), and decreases LH secretion in the peri-ovulation period by about half (54). During heat stress, lower follicular production of oestrogens and ovulation of lower quality oocytes were observed $(21,66)$. The negative consequence of such changes will be formation of a CL which produces a lower amount of progesterone during the next cycle $(60,65)$. These disturbances persist in cow fertility, so even for a longer period of up to a few months after hot days their negative effects can still be recognised in a lower fertility rate (52). It can be presumed that long-lasting hot days cause permanent 
changes in antral follicles, which will develop into dominant follicles in the following cycles (50). To minimise the negative effects of high temperatures on the secretion of hormones and maturation of oocytes, the use of hormonal protocols during this period has been proposed (50). Ullah et al. (58) compared the efficiency of insemination of cows treated and untreated with $\mathrm{GnRH}$ in oestrous during a high temperature period. In the group that received GnRH, $28.6 \%$ of the cows were pregnant after the first insemination, whereas in the control group only $17.7 \%$ were pregnant. Other studies $(2,19)$ also confirmed the hypothesis that administration of GnRH in oestrous during heat stress had a positive impact on the development of follicles and quality of oocytes. The comparison of three different hormonal methods (OvSynch protocol, two-fold $\mathrm{PGF}_{2} \alpha 14$ days apart, and single $\mathrm{PGF}_{2} \alpha$ ) in the summer and winter was performed by Alnimer et al. (1). The conception rates after the first insemination for the above mentioned methods were $36.7 \%, 22.7 \%$, and $26.3 \%$, respectively. It must also be noted that after the third insemination, $83 \%$ of cows in the OvSynch group were pregnant, compared to only $60 \%$ in both other groups. This outcome clearly shows the advantages of the OvSynch protocol over the other hormonal methods.

Cyst treatment. The OvSynch protocol mimics the combined treatment of ovarian cysts with $\mathrm{GnRH}-\mathrm{PGF}_{2} \alpha-$ GnRH (67). Cysts are non-ovulating liquid-filled structures with a diameter of over $25 \mathrm{~mm}$ which persist on the ovary for over 10 days simultaneously with absence of the CL (27). Injection of GnRH causes higher LH secretion from the pituitary gland, which leads to luteinisation of cystic follicles or promotes other follicles to ovulate $(9,62)$. Occasionally, a rupture of the cyst may occur (31). The next important step in this hormonal therapy is $\mathrm{PGF}_{2} \alpha$ injection, to cause luteolysis of luteal tissue (41). The second GnRH injection should then stimulate the follicles of the last wave to ovulation, conditioning the animal for AI. Administering the same hormones as in the classic ovarian cyst treatment, the OvSynch protocol can be used for treatment of cysts, based on the similar hormonal changes it effects. Fricke and Wiltbank (29) proved that despite the presence of a cyst, after applying the above hormones, a follicle may develop and ovulate leading to fertilisation of the oocyte, and the follicle may be fully functional with no other impairment than the cyst. In their study, after performing the OvSynch protocol $71.3 \%$ of cows with cysts had a synchronised cycle and $36.8 \%$ of these cows became pregnant. Among the cows without cysts the treatment efficacy was only slightly better, since $48.8 \%$ of cows were pregnant on the $28^{\text {th }}$ day after AI. These findings have also been confirmed in other studies $(5,31)$. De Rensis et al. (20) compared the effects of the OvSynch protocol and its modification (replacement of the second $\mathrm{GnRH}$ by hCG injection) in lactating cows with ovarian cysts. In cystic cows, which received hCG, cysts disappeared faster. Similar results were also obtained in other studies $(4,18)$, suggesting that injection of hCG instead of GnRH may be one way to improve the treatment effect of the OvSynch protocol on ovarian cysts in dairy cows (20). This improvement is probably based on the fact that hCG acts longer than GnRH and delivers a better clinical effect (37).

\section{OvSynch modifications}

Presynchronisation of ovaries with prostaglandin F2a. As was previously mentioned, presynchronisation with the use of $\mathrm{PGF}_{2} \alpha$ is able to equalise a cycle before the beginning of the OvSynch protocol $(3,34)$. The PreSynch protocol starts with a $\mathrm{PGF}_{2} \alpha$ injection given 12 days before OvSynch (17). This causes the synchronisation of the cyclic activity of the ovaries. There is, therefore, a much higher probability that during the first GnRH injection according to the OvSynch protocol, the follicles of the second wave present on the ovary will be able to develop (17). Other reasearch has suggested that presynchronisation with $\mathrm{PGF}_{2} \alpha$ should include two injections 14 days apart and the OvSynch protocol should begin 11 or 12 days after the second injection $(26,42)$ (Fig. 2). There is also the option of starting the OvSynch seven days after the second injection of $\mathrm{PGF}_{2} \alpha$ (23). El-Zarkouny et al. (26) used the PreSynch programme before OvSynch and obtained an increase of up to $48.8 \%$ in the pregnancy rate after the first AI but only obtained 37.5\% using OvSynch alone. A similar study has been performed by Gumen et al. (35), who achieved an $8 \%$ insemination efficiency gain after the PreSynch protocol.

Double OvSynch as a new presynchronisation schedule. Another modification of the basic OvSynch is Double OvSynch, which proceeds through two OvSynch protocols seven days apart and follows with TAI after the second protocol (Fig. 2) (53). The obtained results showed an even higher pregnancy rate compared to PreSynch outcomes $(23,53,55)$. The final pregnancy rates showed the advantage of Double OvSynch compared to PreSynch: $49.7 \%$ vs $41.7 \%$. The reason for this may be that cows with inactive ovaries after parturition did not respond to the $\mathrm{PGF}_{2} \alpha$ injection during PreSynch. In contrast, the two additional doses of GnRH in Double OvSynch stimulated the ovaries to return to activity. This treatment had no negative consequences in the cows with already active ovaries $(35,53)$. An interesting observation was that the Double OvSynch protocol was much more efficient in heifers $(65.2 \%)$ than in cows (37.5\%) (53). Souza et al. (53) therefore recommend Double OvSynch for heifers, whereas presynchronisation with $\mathrm{PGF}_{2} \alpha$ should be performed in cows because of its better efficiency in that group of animals $(14,50)$. Recent studies comparing these two methods showed worse outcomes, but still the advantageous effects of the Double OvSynch protocol over PreSynch have been confirmed (23). 


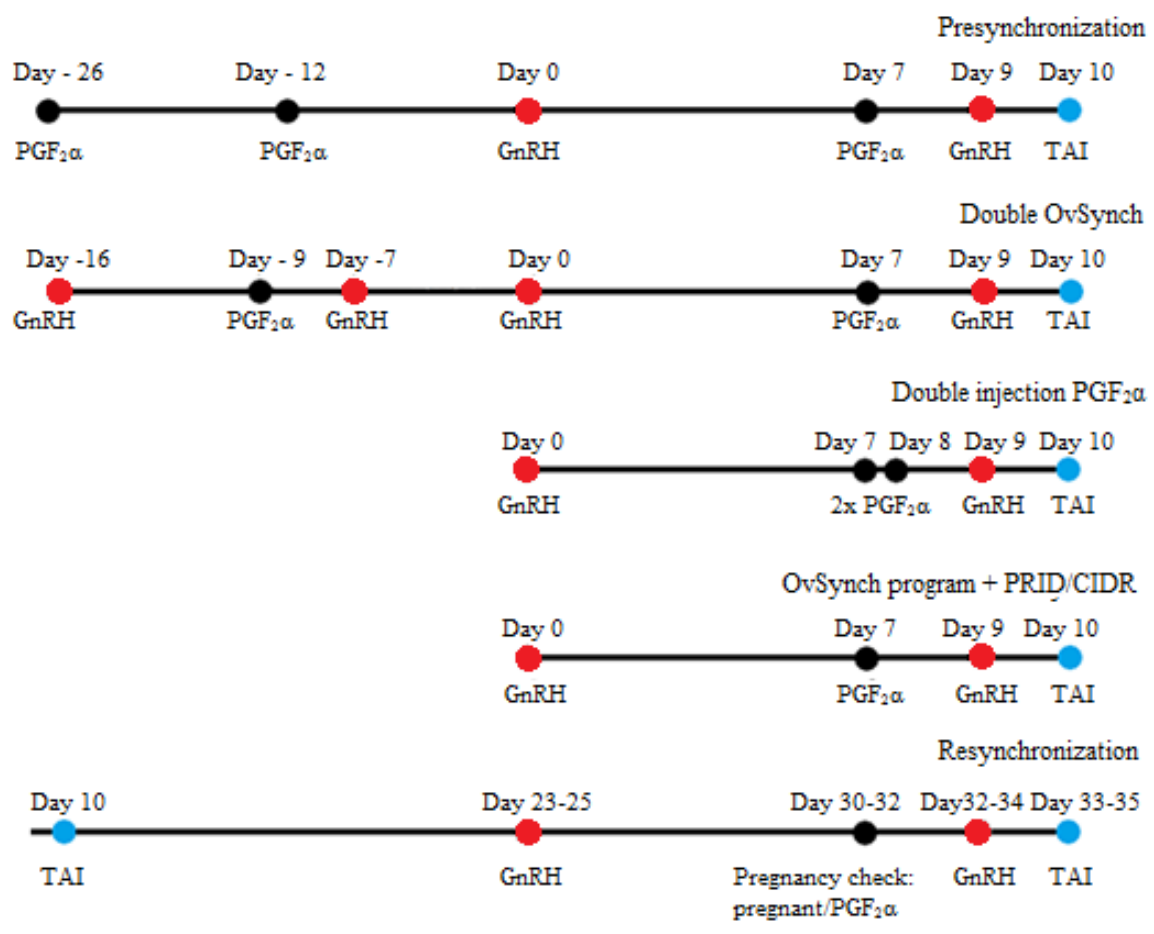

Fig. 2. Schemes of OvSynch modifications (PRID - Progesterone-releasing intra-vaginal device, CIDR - controlled internal drug release containing progesterone, TAI - timed artificial insemination)

Second injection of $\mathrm{PGF}_{2} \alpha$ during OvSynch protocol to improve luteolysis. As was previously mentioned, an important reason for the decreased pregnancy rate after OvSynch is lack of luteolysis after the $\mathrm{PGF}_{2} \alpha$ injection (Fig. 2). The most probable explanation for this phenomenon is the formation of a young corpus luteum after the first GnRH which is not sensitive to prostaglandin $(15,22)$.

Carvalho et al (15) have shown that a double $\mathrm{PGF}_{2} \alpha$ injection during the OvSynch protocol is able to boost luteolysis. In their study, the authors divided cows into four groups. Their $1^{\text {st }}$ group's regimen was OvSynch without any modification, the $2^{\text {nd }}$ group received $\mathrm{GnRH}$ presynchronisation, the $3^{\text {rd }}$ group was medicated with OvSynch with double $\mathrm{PGF}_{2} \alpha$ injection, and the $4^{\text {th }}$ group was assigned a combination of the two previous protocols. The pregnancy rates per artificial insemination (P/AI) by group were $32 \%, 33 \%$, $37 \%$, and $40 \%$, respectively. Cows treated with double $\mathrm{PGF}_{2} \alpha$ injections and with lower P4 concentration on the day of TAI had better reproductive outcomes than cows from the $3^{\text {rd }}$ and $4^{\text {th }}$ groups. The recommended time for the second $\mathrm{PGF}_{2} \alpha$ injection is $24 \mathrm{~h}$ after the first injection without any changes to the times of GnRH injection or TAI $(12,15)$.

Intravaginal devices for maintenance of $\mathrm{CL}$ function. Intravaginal inserts (PRID - progesteronereleasing intra-vaginal device or CIDR - controlled internal drug release) containing progesterone may also be included into the OvSynch protocol. This method of synchronisation was performed by Bisinotto et al. (10). Cows with detected CL on the ovaries were selected for this research and divided into two groups. In both groups a basic OvSynch protocol was applied. Additionally, cows from the experimental group received a progesterone device for seven days at the time of the first GnRH, while the control group was treated without any modification (Fig. 2). Unexpectedly, a slightly higher pregnancy rate was noticed in the control group $(45 \%)$, than in the experimental group $(40.5 \%)$. In the same study better results were obtained in heifers $(40.5 \%)$ than in cows $(35.7 \%)$ and better in cows which were inseminated for the first time after parturition $(41.7 \%)$ than in reinseminated cows $(34.7 \%)$. An explanation of these results is an increased level of progesterone, which reduces the LH pulse frequency. As a consequence, altered follicular growth and ovulation were possible (27). Another explanation is lower amplitude of secreted LH pulses after the GnRH injection (33).

On the other hand, some studies indicated the positive influence of progesterone-releasing devices on conception rate in OvSynch-synchronised cows. El-Zarkouny et al. (26) reached a conception rate of $59.3 \%$, while Bisinotto et al. (11) noted 51.3\%, after a protocol with a gestagen insert but also with a double injection of $\mathrm{PGF}_{2} \alpha$ on day 7 of OvSynch. Revah et al. (49) claimed that a high level of progesterone in the follicular phase causes the reduction of LH secretion, which improves the quality of oocytes. In consequence, and with reference to the studies cited above, there are difficulties in clearly defining the effects of progesterone supplementation during such an OvSynch protocol. These effects are caused by, inter alia, 
progesterone level's subjection to many factors such as the level of dry matter intake, milk yield, and metabolic status $(51,59)$. As a consequence, application of an intravaginal device and the concentration of progesterone caused by this treatment can be insufficient in many cows, because of a very high turnover rate of this hormone.

Resynchronisation. Besides presynchronisation, there is also a possibility to resynchronise ovulation using the OvSynch protocol (5). This schedule assumes a consecutive AI if the cows were detected as not pregnant on days 30-32 after the first AI (6). The next OvSynch can be started at that moment, but it is also possible to shorten the time needed for the next AI by injecting the first GnRH dose seven days before the pregnancy check (22). This allows the injection of $\mathrm{PGF}_{2} \alpha$ at the time of the pregnancy check, and as a consequence three days later a cow can already be reinseminated, according to the basic OvSynch protocol. The efficacy of resynchronisation started on the $23^{\text {rd }}-25^{\text {th }}$ days varied from $23 \%$ to $50 \%(7,16,30)$ and when started on the day of the pregnancy check $\left(30^{\text {th }}-32^{\text {nd }}\right.$ days $)$ it fell within $25.2 \%$ to $33.6 \%(5,16)$. Bartolome et al. $(5,6,7)$ compared the efficiency of resynchronisation using OvSynch started in different phases of the oestrus cycle. The highest pregnancy rate was achieved in the group in which OvSynch was begun in dioestrous $(35.9 \%)$. In the group with ovarian cysts the pregnancy rate was the lowest $(20.2 \%)$. To improve the effectiveness of resynchronisation, the use of progesterone devices, another GnRH injection, or shorter hormonal programmes are suggested; however, the results of these studies are inconsistent $(7,22)$.

\section{Conclusions}

Implementation of hormonal protocols, which are able to synchronise the oestrus cycle, provides many opportunities for reproductive management. A major advantage of some protocols is the possibility of timed AI, which makes work with the animals easier and less time-consuming. An additional effect is minimising the problem of unobserved heat. OvSynch, as one of the most popular hormonal protocols, can be used both for routine cycle synchronisation and for treatment of cystic ovarian disease, silent heat, or heat stress. This method is more effective when used for cows rather than heifers. To improve insemination and pregnancy rates after OvSynch, some modifications of its basic protocol are currently being tested. These modified hormonal protocols should overcome the problems with the development of follicles or corpora lutea not responding to $\mathrm{GnRH}$ or $\mathrm{PGF}_{2} \alpha$. Another weakness to address is insufficiency of the corpus luteum, which may be ameliorated by the use of intravaginal progesterone devices.
Conflict of Interests Statement: The authors declare that there is no conflict of interests regarding the publication of the article.

Financial Disclosure Statement: This investigation was financed by the University of Warmia and Mazury in Olsztyn, Faculty of Veterinary Medicine.

Animal Rights Statement: None required.

\section{References}

1. Alnimer M., De Rosa G., Grasso F., Napolitano F., Bordi A.: Effect of climate on the response to three oestrous synchronisation techniques in lactating dairy cows. Anim Reprod Sci 2002, 71, 157-168.

2. Arechiga C.F., Staples C.R., McDowell L.R., Hansen P.J.: Effects of timed insemination and supplemental $\beta$-carotene on reproduction and milk yield of dairy cows under heat stress. J Dairy Sci 1998, 81, 390-402.

3. Ayres H., Ferreira R.M., Cunha A.P., Araújo R.R., Wiltbank M.C.: Double Ovsynch in high-producing dairy cows: effects on progesterone concentrations and ovulation to GnRH treatments. Theriogenology 2013, 79, 159-164.

4. Bartolome J.A., Archbald L.F., Morresey P., Hernandez J., Tran T., Kelbert D., Long K., Risco C.A., Thatcher W.W.: Comparison of synchronization of ovulation and induction of estrus as therapeutic strategies for bovine ovarian cysts in the dairy cow. Theriogenology $2000,53,815-825$.

5. Bartolome J.A., Silvestre F.T., Kamimura S., Arteche A.C.M., Melendez P., Kelbert D., McHale J., Swift K., Archbald L.F., Thatcher W.W.: Resynchronization of ovulation and timed insemination in lactating dairy cows I: use of the Ovsynch and Heatsynch protocols after non-pregnancy diagnosis by ultrasonography. Theriogenology 2005; 63, 1617-1627.

6. Bartolome J.A., Sozzi A., McHale J., Melendez P., Arteche A.C.M., Silvestre F.T., Kelbert D., Swift K., Archbald L.F., Thatcher W.W.: Resynchronization of ovulation and timed insemination in lactating dairy cows, II: assigning protocols according to stages of the estrous cycle, or presence of ovarian cysts or anestrus. Theriogenology 2005, 63, 1628-1642.

7. Bartolome J.A., Sozzi A., McHale J., Swift K., Kelbert D., Archbald L.F., Thatcher W.W.: Resynchronization of ovulation and timed insemination in lactating dairy cows III. Administration of GnRH 23 days post AI and ultrasonography for nonpregnancy diagnosis on day 30 Theriogenology 2005, 63, 1643-1658.

8. Bello N.M., Steibel J.P., Pursley J.P.: Optimizing ovulation to first GnRH improved outcomes to each hormonal injection of Ovsynch in lactating dairy cows. J Dairy Sci 2006, 89, 3413-3424.

9. Bierschwal C.J., Garverick H.A., Martin C.E., Youngquist R.S., Cantley T.C., Brown M.D.: Clinical response of dairy cows with ovarian cysts to GnRH. J Anim Sci 1975, 41, 1660-1665.

10. Bisinotto R.S., Pansani M.B., Castro L.O., Narciso C.D., Sinedino L.D.P., Martinez N., Carneiro P.E., Thatcher W.W., Santos J.E.P.: Effect of progesterone supplementation on fertility responses of lactating dairy cows with corpus luteum at the initiation of the Ovsynch protocol. Theriogenology 2015, 83, 257-265.

11. Bisinotto R.S., Ribeiro E.S., Martins L.T., Marsola R.S., Greco L.F., Favoreto M.G., Risco C.A., Thatcher W.W., Santos J.E.P.: Effect of interval between induction of ovulation and artificial insemination (AI) and supplemental progesterone for resynchronization on fertility of dairy cows subjected to a 5-d timed AI program. J Dairy Sci 2010, 93, 5798-5808. 
12. Brusveen D.J., Souza A.H., Wiltbank M.C.: Effects of additional prostaglandin F2 $\alpha$ and estradiol-17 $\beta$ during Ovsynch in lactating dairy cows. J Dairy Sci 2009 92, 1412-1422.

13. Butler W.R.: Energy balance relationships with follicular development, ovulation and fertility in postpartum dairy cows. Livest Prod Sci 2003, 83, 211-278.

14. Cartmill J.A., El-Zarkouny S.Z., Hensley B.A., Lamb G.C., Stevenson J.S.: Stage of cycle, incidence, and timing of ovulation, and pregnancy rates in dairy cattle after three timed breeding protocols. J Dairy Sci 2001, 84 , 1051-1059.

15. Carvalho P.D., Fuenzalida M.J., Ricci A., Souza A.H., Barletta R.V., Wiltbank M.C., Fricke P.M.: Modifications to Ovsynch improve fertility during resynchronization: Evaluation of presynchronization with gonadotropin-releasing hormone $6 \mathrm{~d}$ before initiation of Ovsynch and addition of a second prostaglandin F2 $\alpha$ treatment. J Dairy Sci 2015, 98, 8741-8752.

16. Chebel R.C., Santos J.E.P., Cerri R.L.A., Galvao K.N., Juchem S.O., Thatcher W.W.: Effect of resynchronization with $\mathrm{GnRH}$ on day 21 after artificial insemination on pregnancy rate and pregnancy loss in lactating dairy cows. Theriogenology 2003, 60, 1389-1399.

17. Cordoba M.C., Fricke P.M.: Evaluation of two hormonal protocols for synchronization of ovulation and timed artificial insemination in dairy cows managed in grazing-based dairies. J Dairy Sci 2001, 84, 2700-2708.

18. Crane M.B., Bartolome J., Melendez P., de Vries A., Risco C., Archbald L.F.: Association between milk production and treatment response of ovarian cysts in lactation dairy cows using the Ovsynch protocol. Theriogenology 2006, 66, 1243-1248.

19. De La Sota R.L., Burke J.M., Risco C.A., Moreira F., DeLorenzo M.A., Thatcher W.W.: Evaluation of timed insemination during summer heat stress in lactating dairy cattle. Theriogenology 1998, 49, 761-770.

20. De Rensis F., Bottarelli E., Battioni F., Capelli T., Techakumphu M., García-Ispierto I., López-Gatius F.: Reproductive performance of dairy cows with ovarian cysts after synchronizing ovulation using GnRH or hCG during the warm or cool period of the year. Theriogenology 2008, 69, 481-484.

21. De Rensis F., Scaramuzzi R.J.: Heat stress and seasonal effects on reproduction in the dairy cow-a review. Theriogenology 2003, 60, 1139-1151.

22. Dewey S.T., Mendonca L.G., Lopes G. Jr., Rivera F.A., Guagnini F., Chebel R.C., Bilby T.R.: Resynchronization strategies to improve fertility in lactating dairy cows utilizing a presynchronization injection of GnRH or supplemental progesterone: I. Pregnancy rates and ovarian responses. J Dairy Sci 2010, 93, 4086-4095.

23. Dirandeh E., Rezaei Roodbari A., Colazo M.G.: DoubleOvsynch, compared with presynch with or without GnRH, improves fertility in heat-stressed lactating dairy cows. Theriogenology 2015, 83, 438-443.

24. Dirandeh E.: Starting Ovsynch protocol on day 6 of first postpartum estrous cycle increased fertility in dairy cows by affecting ovarian response during heat stress. Anim Reprod Sci 2014, 149, 135-140.

25. Dobson H., Esslemont R.J.: Stress and its effects on fertility of the dairy cow. Adv Dairy Technol 2002, 14, 193-206.

26. El-Zarkouny S.Z., Cartmill J.A., Hensley B.A., Stevenson J.S.: Pregnancy in dairy cows after synchronized ovulation regimens with or without presynchronization and progesterone. J Dairy Sci 2004, 87, 1024-1037.

27. Farin P.W., Estill C.T.: Infertility due to abnormalities of the ovaries in cattle. Food Anim Pract 1993, 9, 291-308.

28. Firk R., Stamer E., Junge W., Krieter J.: Automation of oestrus detection in dairy cows: a review. Livest Prod Sci 2002, 75, 219-232.

29. Frickce P.M., Wiltbank M.C. Effect of milk production on the incidence of double ovulation in dairy cows. Theriogenology 1999, 52, 1133-1143.

30. Fricke P.M., Caraviello D.Z., Weigel K.A., Welle M.L.: Fertility of dairy cows after resynchronization of ovulation at three intervals following first timed insemination. J Dairy Sci 2003 , $86,3941-3950$

31. Garverick H.A.: Ovarian follicular cysts in dairy cows. J Dairy Sci 1997, 80, 995-1004.

32. Ginther O.J., Wiltbank M.C., Fricke P.M., Gibbons J.R., Kot K.: Selection of the dominant follicle in cattle. Biol Reprod 1996, $55,1187-1194$

33. Giordano J.O., Fricke P.M., Guenther J.N., Lopes G. Jr., Herlihy M.M., Nascimento A.B., Wiltbank M.C.: Effect of progesterone on magnitude of the luteinizing hormone surge induced by two different doses of gonadotropin-releasing hormone in lactating dairy cows. J Dairy Sci 2012, 95, 3781-3793.

34. Gumen A., Guenther J.N., Wiltbank M.C.: Follicular size and response to Ovsynch versus detection of estrus in anovular and ovular lactating dairy cows. J Dairy Sci 2003, 86, 3184-3194.

35. Gumen A., Keskin A., Yilmazbas-Mecitoglu G., Karakaya E., Alkan A., Okut H., Wiltbank M.C.: Effect of presynchronization strategy before Ovsynch on fertility at first service in lactating dairy cows. Theriogenology 2012, 78, 1830-1838.

36. Kasimanickam R., Cornwell J.M., Nebel R.L.: Fertility following fixed-time AI or insemination at observed estrus in Ovsynch and Heatsynch programs in lactating dairy cow. Theriogenology 2005, 63, 2550-2559.

37. Kinser A.R., Gibson M.F., Vincent D.L., Scheffrahn N.S., Kesler D.J.: Ovarian responses of seasonally anestrous ewes administered progesterone, PMSG, hCG and(or) GnRH. Theriogenology 1983, 19, 449-464.

38. Lopez H., Satter L.D., Wiltbank M.C.: Relationship between level of milk production and estrous behavior of lactating dairy cows. Anim Reprod Sci 2004, 81, 209-223.

39. López-Gatius F., Santolaria P., Munder I., Yaniz J.L.: Walking activity at estrus and subsequent fertility in dairy cows. Theriogenology 2005, 63, 1419-1429.

40. Mejia M.E., Lacau-Mengido I.M.: Endometritis treatment with a $\mathrm{PGF}_{2} \alpha$ analog does not improve reproductive performance in a large dairy herd in Argentina. Theriogenology 2005, 63, 1266-1276.

41. Nanda A.S., Ward W.R., Williams P.C., Dobson H.: Retrospective analysis of the efficacy of different hormone treatments of cystic ovarian disease in cattle. Vet Rec 1988, 122, 1155-1158.

42. Navanukraw C., Redmer D.A., Reynolds L.P., Kirsch J.D., Grazul-Bilska A.T., Fricke P.M.: A modified presynchronization protocol improves fertility to timed artificial insemination in lactating dairy cows. J Dairy Sci 2004, 87, 1551-1557.

43. Opsomer G., Grohn Y.T., Hertl J., Coryn M., Deluyker H., de Kruiff A.: Risk factors for post partum ovarian dysfunction in high producing dairy cows in Belgium: a field study. Theriogenology 2000, 53, 841-857.

44. Perry G.A., Smith M.F., Lucy M.C., Green J.A., Parks T.E., MacNeil M.D., Roberts A.J., Geary T.W.: Relationship between follicle size at insemination and pregnancy success. PNAS 2005 , 102, 5268-5273.

45. Pursley J.R., Kosorok M.R., Wiltbank M.C.: Reproductive management of lactating dairy cows using synchronization of ovulation. J Dairy Sci 1997, 80, 301-306.

46. Pursley J.R., Mee M.O., Wiltbank M.C.: Synchronization of ovulation in dairy cows using PGF2 $\alpha$ and GnRH. Theriogenology 1995, 44, 915-923.

47. Pursley J.R., Silcox R.W., Wiltbank M.C.: Effect of time of artificial insemination on pregnancy rates, calving rates, pregnancy loss, and gender ratios after synchronization of ovulation in lactating dairy cows. J Dairy Sci 1998, 81, 2139-2144.

48. Pursley J.R., Wiltbank M.C., Stevenson J.S., Ottobre J.S., Garverick H.A., Anderson L.L.: Pregnancy rates per artificial insemination for cows and heifers inseminated at a synchronized ovulation or synchronized estrus. J Dairy Sci 1997, 80, 295-300.

49. Revah I., Butler W.R.: Prolonged dominance of follicles reduced viability of bovine oocytes. J Reprod Fertil 1996, 106, 39-47. 
50. Roth Z., Arav A., Bor A., Zeron Z., Braw-Tal R., Wolfenson D.: Improvement of quality of oocytes collected in the autumn by enhanced removal of impaired follicles from previously heatstressed cows. Reproduction 2001, 122, 737-744.

51. Sangsritavong S., Combs D.K., Sartori R., Armentano L.E., Wiltbank M.C.: High feed intake increases liver blood flow and metabolism of progesterone and estradiol-17 $\beta$ in dairy cattle. J Dairy Sci 2002, 85, 2831-2842.

52. Sianangama P.C., Rajamahendran R.: Effect of human chorionic gonadotropin administered at specific times following breeding on milk progesterone and pregnancy in cows. Theriogenology 1992, 38, 85-96.

53. Souza A.H., Ayres H., Ferreira R.M., Wiltbank M.C.: A new presynchronization system (Double-Ovsynch) increases fertility at first postpartum timed AI in lactating dairy cows. Theriogenology 2008, 70, 208-215.

54. Souza A.H., Gumen A., Silva E.P., Cunha A.P., Guenther J.N., Peto C.M., Caraviello D.Z., Wiltbank M.C.: Supplementation with estradiol-17 $\beta$ before the last gonadotropin-releasing hormone injection of the Ovsynch protocol in lactating dairy cows. J Dairy Sci 2007, 90, 4623-4634.

55. Stevenson J.L., Dalton J.C., Santos J.E.P., Sartori R., Ahmadzadeh A., Chebel R.C.: Effect of synchronization protocols on follicular development and estradiol and progesterone concentrations of dairy heifers. J Dairy Sci 2008, 91, 3045-3056.

56. Stevenson J.S., Kobayashi Y., Thomson K.E.: Reproductive performance of dairy cows in various programmed breeding systems including OvSynch and combinations of gonadotropinreleasing hormone and prostaglandin F2 $\alpha$. J Dairy Sci 1999, 82, 506-515.

57. Thatcher W.W., Moreira F., Pancarci S.M., Bartolome J.A., Santos J.E.P.: Strategies to optimize reproductive efficiency by regulation of ovarian function. Domest Anim Endocrinol 2002, 23, 243-254

58. Ullah G., Fuquay J.W., Keawkhong T., Clark B.L., Pogue D.E., Murphey E.J.: Effect of gonadotropin-releasing hormone at estrus on subsequent luteal function and fertility in lactating holsteins during heat stress. J Dairy Sci 1996, 79, 1950-1953.
59. Vasconcelos J.L.M., Sangsritavong S., Tsai S.J., Wiltbank M.C.: Acute reduction in serum progesterone concentrations after feed intake in dairy cows. Theriogenology 2003, 60, 795-807.

60. Vasconcelos J.L.M., Sartori R., Oliveira H.N., Guenther J.G., Wiltbank M.C.: Reduction in size of the ovulatory follicle reduces subsequent luteal size and pregnancy rate. Theriogenology 2001, 56, 307-314.

61. Walsh S.W., Williams E.J., Evans A.C.O.: A review of the causes of poor fertility in high milk producing dairy cows. Anim Reprod Sci 2011, 123, 127-138.

62. Whitmore H.L., Hurtgen J.P., Mather E.C., Seguin B.E.: Clinical response of dairy cattle with ovarian cysts to single or repeated treatments of gonadotropin-releasing hormone. J Am Vet Med Assoc 1979, 174, 1113-1115.

63. Wiltbank M.C., Lopez H., Sartori R., Sangsritavong S., Gumen A.: Changes in reproductive physiology of lactating dairy cows due to elevated steroid metabolism. Theriogenology 2006, 65, 17-29.

64. Wiltbank M.C., Pursley J.R.: The cow as an induced ovulator: timed AI after synchronization of ovulation. Theriogenology 2014, 81, 170-185.

65. Wiltbank M.C., Sartori R., Herlihy M.M., Vasconcelos J.L.M., Nascimento A.B., Souza A.H., Ayres H., Cunha A.P., Keskin A., Guenther J.N., Gumen A.: Managing the dominant follicle in lactating dairy cows. Theriogenology 2011, 76, 1568-1582.

66. Wolfenson D., Lew B.J., Thatcher W.W., Graber Y., Meidan R.: Seasonal and acute heat stress effects on steroid production by dominant follicles in cows. Anim Reprod Sci 1997, 47, 9-19.

67. Yaniz J.L., Murugavel K., López-Gatius F.: Recent developments in oestrous synchronization of postpartum dairy cows with and without ovarian disorders. Reprod Domest Anim 2004, 39 , 86-93.

68. Yrjo T.G., Hollis N.E., McCulloch C.E., Saloniemi H.S.: Epidemiology of reproductive disorders in dairy cattle: associations among host characteristics, disease and production. Prev Vet Med 1990, 8, 25-39.

69. Zduńczyk S., Janowski T., Raś M.: Current views on the phenomenon of silent heat in cows. Med Weter 2005, 61, $726-729$. 